\title{
Memory for literary metaphors
}

\author{
RICHARD J. HARRIS \\ Kansas State University, Manhattan, Kansas 66506
}

\begin{abstract}
Three studies used a forced-choice recognition task to compare memory for metaphorical and nonmetaphorical sentences expressing the same idea. Materials were quotations from Shakespeare and adaptations thereof. Results, using both sentence lists and play synopses with quoted excerpts, found that metaphors were correctly recognized more frequently than nonmetaphors and that false alarms tended in a more, rather than less, metaphorical direction. This finding differed both from a naive theory, predicting metaphors to be more difficult, and from results of studies of nonliterary metaphors finding no metaphor-nonmetaphor differences.
\end{abstract}

Although metaphor is a pervasive phenomenon of language that has only recently been seriously studied in psychology (e.g., Billow, 1977; Honeck, Riechmann, \& Hoffman, 1975; Malgady \& Johnson, 1977; Ortony, Reynolds, \& Arter, 1978; Verbrugge, 1977), it has long been recognized as an important ingredient in poetry, drama, and other literary writings.

Some recent studies have examined memory and comprehension of ordinary language metaphors. Harris (1979) found no difference between metaphors, dead metaphors, and nonmetaphors in terms of numbers correct in either cued recall or forced-choice recognition memory tasks. Materials used were short sentences in contemporary language. This finding was replicated in an incidental learning situation by Harris, Lahey, and Marsalek (in press).

Although there has been little experimental study of literary metaphor, even difficult literary metaphors can be successfully used as experimental materials. Harris (1976) asked subjects to paraphrase quotations from Shakespeare and measured the latency to initiate the paraphrase. No latency differences were found between metaphorical and nonmetaphorical sentences, and results were used to argue against a two-stage model of metaphor processing, whereby a literal meaning must be constructed in order to compute the metaphorical meaning. The present study used the same materials in recognition memory studies both within and outside of their normal dramatic context. The design used sets of sentences that express as close to the same thought as possible either metaphorically or nonmetaphorically. This allows a test of the naive theory that metaphors should be harder to remember than nonmetaphorical equivalents, and it also allows comparison of results

This research was supported by Grant MH 28493-01 from NIMH and a grant from the Kansas State University Bureau of General Research. Appreciation is expressed to Virginia Dicks, Pat Martin, and Don Miller for data collection and to Gregory Monaco for his helpful comments on the manuscript. Requests for reprints should be sent to Richard J. Harris, Department of Psychology, Anderson Hall, Kansas State University, Manhattan, Kansas 66506. with earlier studies using non-Shakespearean metaphors constructed especially for research purposes.

\section{EXPERIMENT 1}

\section{Method}

Subjects. The subjects were 32 native English-speaking undergraduate psychology students at Kansas State University who received extra course credit for participation. They were run in small groups of one to six. In addition, 72 other subjects from the same pool participated in two rating tasks.

Materials and Design. A total of 36 metaphorical quotations were selected from the following plays by William Shakespeare: Hamlet, Macbeth, Romeo and Juliet, Richard II, Henry IV (Part 1), Othello, Titus Andronicus, and The Merchant of Venice. Each sentence or phrase was readily, although not necessarily instantly, interpretable out of context to a modern listener and involved an interaction of semantic domains characteristic of metaphors, for example personification ("The wind sits in the shoulder of your sail"), concretizing of an abstraction ("Confused events new hatched to the woeful time"), and man-object comparison ("A son who is amongst a grove the very straightest plant"). Highly familiar passages from Shakespeare were not used.

For each original metaphor $\left(\mathrm{M}_{\mathrm{o}}\right)$, three other sentences (or phrases) were written. A new metaphor $\left(M_{n}\right)$ had the same abstract meaning as the original metaphor $\left(\mathrm{M}_{0}\right)$ but used a different literal semantic domain. Two nonmetaphorical sentences $\left(\mathrm{N}_{1}\right.$ and $\left.\mathrm{N}_{2}\right)$ expressed the same abstract meaning as the original metaphor but stated that meaning directly without metaphor. All four sentences in any given sentence set contained exactly the same sentence structure and differed only in between one and four content words necessary to express the metaphor. The four sentences were constructed to be as much alike as possible in abstract meaning and all in Shakespearean style but making sense in isolation. Three sample sentence sets appear in Table 1.

The sentences were then rated by 28 new subjects for "metaphoricity," how metaphorical the sentence was on a scale from 1 (completely unmetaphorical) to 5 (highly and novelly metaphorical), and by 44 subjects for comprehensibility, also on a scale from 1 (very hard to understand) to 5 (easily understandable). Counterbalancing was such that all of the subjects on each rating task rated 36 sentences, exactly 1 from each sentence set, with the same numbers of $M_{0}, M_{n}, N_{1}$, and $N_{2}$ sentences, in random but constant order for all subjects rating that list. The mean metaphoricity ratings for the $\mathrm{M}_{\mathbf{o}}, \mathrm{M}_{\mathbf{n}}$, $\mathrm{N}_{1}$, and $\mathrm{N}_{2}$ sentences were $3.56,3.49,2.61$, and 2.69, respectively, while the mean comprehensibility ratings were 3.47 , $3.46,3.68$, and 3.51 , respectively. Thus the metaphorical and 
Table 1

Sample Sentence Sets

$M_{0}$ Myself eating the bitter bread of banishment.*

$\mathbf{M}_{\mathbf{n}}$ Myself tasting the acrid wine of banishment.

$\mathrm{N}_{1}$ Myself sustaining the sorry state of banishment.

$\mathrm{N}_{2}$ Myself enduring the cheerless plight of banishment.

$M_{0}$ Your bait of falsehood takes this carp of truth.**

$M_{n}$ Your seduction of falsehood takes this wench of truth.

$\mathrm{N}_{1}$ Your offering of falsehood takes this gift of truth.

$\mathrm{N}_{2}$ Your act of falsehood takes this result of truth.

$M_{0}$ He hates the slime that sticks on filthy deeds.***

$M_{n}$ He hates the venom that oozes from poison deeds.

$\mathrm{N}_{1}$ He hates the rancor that stays on cruel deeds.

$\mathrm{N}_{2}$ He hates the malice that comes from dastardly deeds.

*Richard II, III: 1

**Hamlet, II: 1

***Othello, V: 2

nonmetaphorical items did actually differ from each other in perceived metaphoricity but not in comprehensibility.

Four acquisition lists of 36 sentences each were constructed. Each of the four lists contained 1 member from each of the 36-sentence sets, with 9 each of $M_{0}, M_{n}, N_{1}$, and $N_{2}$. A given sentence occurred in one list in each of its four forms.

In order to attenuate serial position and short-term memory effects, three filler items occurred at the beginning and three at the end of each acquisition list. These items were constant for all subjects and consisted of familiar passages from Shakespeare that were not metaphorical ("A horse, a horse, my kingdom for a horse"; "To be or not to be, that is the question").

Procedure. The subjects were told that they were participating in an experiment studying how people understand the writings of great literature. They were told that they would hear a taped list of sentences from the plays of William Shakespeare. They were told to listen carefully and try to understand each sentence, because afterward they would be asked some questions about the sentences. They were told that they did not need the context of the play to understand the sentences, but that the archaic style of Shakespeare might introduce some difficulty and would thus require close attention.

The list of 36 experimental and 6 filler sentences was then read on tape clearly and with normal intonation with a 1 -sec pause between sentences. After the conclusion of the tape, all subjects received the same answer sheet, that is, all four possible versions of each sentence, two metaphorical and two nonmetaphorical, in counterbalanced order across items. They were asked to check the one of the four sentences that had occurred in exactly the same form on the tape. There was no time limit on this task.

\section{Results and Discussion}

The mean number of each type of recognition response appears in Table 2. Analyses of variance run on the numbers of correctly recognized sentences showed a significantly greater number of correct responses to metaphors than to nonmetaphors $\left[\mathrm{F}_{1}(1,31)=11.19\right.$, $\left.F_{2}(1,35)=8.08, \min F^{\prime}(1,65)=4.69, p<.05\right]$. Similar analyses showed a significantly greater number of false recognitions of the same type of item (i.e., new metaphor to metaphor and new nonmetaphor to nonmetaphor) to metaphors than to nonmetaphors $\left[F_{1}(1,31)=13.79, \quad F_{2}(1,35)=6.93, \quad \min F^{\prime}(1,62)=\right.$ $4.61, \mathrm{p}<.05]$. Finally, more false recognitions of the opposite type of item were made to nonmetaphors than to metaphors $\left[F_{1}(1,31)=36.05, \quad F_{2}(1,35)=16.55\right.$, $\left.\min \mathrm{F}^{\prime}(1,60)=11.34, \mathrm{p}<.01\right]$.
Because of the obvious nonindependence of the data in the above analyses and the fact that differences were obtained, an additional check was performed on the direction of the false recognitions. Frequencies of same-type and opposite-type responses were recomputed, correcting for the different total number of correct responses to metaphorical and nonmetaphorical sentences. On the basis of the corrected frequencies, a sign test was performed on the numbers of shifts to more and less metaphorical responses. The results of the analyses of variance were upheld $(p<.05)$ in that there were more false recognitions of more metaphorical than less metaphorical distractors.

A significant effect of input sentence type was obtained, with metaphors being recognized correctly more of ten than nonmetaphors. Experiment 2 was an attempt to replicate Experiment 1, but with the Shakespearean metaphors in their natural narrative contexts, rather than abstracted from discourse as they were in Experiment 1. Previous work (Bransford \& Johnson, 1973; Ortony et al., 1978) has shown that extraction of a sentence from its context or theme may interact with the meaning, and thus with memory, in some important ways. The Shakespearean materials provide an ideal opportunity to study metaphors in context, since their intended and original use was in a meaningful drama. For obvious practical reasons, subjects did not hear an entire play, but rather a play synopsis with dramatic readings of critical passages inserted at the appropriate times.

\section{EXPERIMENT 2}

\section{Method}

Subjects. The subjects were 48 native English-speaking undergraduate psychology students at Kansas State University; they received extra course credit for participation and were run in eight groups of six.

Material and Design. Materials consisted of 26 of the 36 passages from Shakespeare used in Experiment 1. Of these passages, five were from Hamlet, six from Macbeth, seven from Romeo and Juliet, and eight from Richard II and Henry IV (Part 1) (two plays making one continuous story and treated as one narrative unit in the experiment). For each of the four stories, the passages were recorded on tape embedded in several lines of context from the play. The mean length of these passages in context was 7.58 lines, with a range of 3-13. In most cases the critical line appeared near the middle of the passage, although in some cases unity of the passage out of context required the critical line to be near the beginning or end of the passage. Every passage had two versions, identical except for one containing the $M_{0}$ line, the original Shakespeare, and the other

Table 2

Experiment 1: Mean Number of Responses (Out of 18)

\begin{tabular}{cccc}
\hline & \multicolumn{3}{c}{ Recognition Type } \\
\cline { 2 - 4 } $\begin{array}{c}\text { Input Sentence } \\
\text { Type }\end{array}$ & Correct & Same Type & $\begin{array}{c}\text { Opposite } \\
\text { Type }\end{array}$ \\
\hline Metaphor & 9.09 & 4.18 & 4.72 \\
Nonmetaphor & 7.00 & 2.50 & 8.50 \\
\hline
\end{tabular}


containing the $\mathrm{N}_{1}$ or $\mathrm{N}_{2}$ line substituted in its place. Five of the passages involved dialogues of two male characters, while the rest were monologues by a male character.

Procedure. The subjects were told that the experiment was a study in how well they understood works of great literature and how such works can be presented in order to make them most understandable. They were told that they would hear the experimenter read a brief synopsis of the story of four plays by Shakespeare. At certain points in the synopsis, the experimenter would stop reading and play a tape recording of a dramatic reading from that portion of the play. The synopsis read by the experimenter provided the appropriate context for the taped passages. The subjects were told to listen carefully to the synopsis and the dramatic readings because afterward they would be asked some questions about them. The passages on tape were recorded by a former professional actor and an amateur actor from the local community theater. After the synopsis and readings from each play, the subject was handed a sheet of paper with a forced-choice recognition task of the five to eight critical sentences in that set of readings. Sets of four sentences $\left(M_{0}, M_{n}, N_{1}, N_{2}\right)$ appeared in the same order they had occurred in the play. In every case the subject was to check the sentence he/she had heard on the tape. Every subject had heard half of the critical sentences in the $M_{0}$ form and half in either the $\mathrm{N}_{1}$ or $\mathrm{N}_{2}$ form, with an equal number of subjects hearing each item in each form. Also, every play occurred in each temporal position of presentation $(1,2,3$, or 4$)$ for 12 subjects. Within each sentence set on the answer sheet, the four sentences in the set were in random order but constant across all subjects. Mean comprehensibility ratings of the critical sentences in Experiment 2 were 3.28 and 3.38 for metaphorical and nonmetaphorical sentences, respectively.

\section{Results and Discussion}

The results were tabulated and analyzed as in Experiment 1 ; the mean numbers of correct, same-type, and opposite-type responses appear at the top of Table 3 . As in Experiment 1, there were a significantly greater number of correct recognitions of metaphors than nonmetaphors $\quad\left[F_{1}(1,47)=49.82, \quad F_{2}(1,25)=12.27\right.$, $\left.\min F^{\prime}(1,38)=9.85, p<.01\right]$ and a significantly greater number of false alarms to the opposite type of sentence for the nonmetaphorical input sentences $\left[F_{1}(1,47)=\right.$ $\left.32.69, F_{2}(1,25)=8.09, \min F^{\prime}(1,38)=6.49, p<.05\right]$. A sign test on the corrected totals of false recognitions in a more and a less metaphorical direction was significant at the .05 level. The results thus supported Experiment 1 , in that metaphors were remembered better than nonmetaphors and false recognitions went in a more, rather than less, metaphorical direction.

Although the better recognition of metaphors compared to nonmetaphors has been demonstrated using

Table 3

Experiments 2 and 3: Mean Number of Responses (Out of 13)

\begin{tabular}{|c|c|c|c|c|}
\hline & \multirow{2}{*}{$\begin{array}{c}\text { Input } \\
\text { Sentence } \\
\text { Type }\end{array}$} & \multicolumn{3}{|c|}{ Recognition Type } \\
\hline & & Correct & $\begin{array}{l}\text { Same } \\
\text { Type }\end{array}$ & $\begin{array}{c}\text { Opposite } \\
\text { Type }\end{array}$ \\
\hline Experiment 2 & $\begin{array}{l}\text { Metaphor } \\
\text { Nonmetaphor }\end{array}$ & $\begin{array}{l}6.69 \\
4.43\end{array}$ & $\begin{array}{l}2.73 \\
2.73\end{array}$ & $\begin{array}{l}3.56 \\
5.94\end{array}$ \\
\hline Experiment 3 & $\begin{array}{l}\text { Metaphor } \\
\text { Nonmetaphor }\end{array}$ & $\begin{array}{l}7.04 \\
4.73\end{array}$ & $\begin{array}{l}2.18 \\
2.77\end{array}$ & $\begin{array}{l}3.77 \\
5.45\end{array}$ \\
\hline
\end{tabular}

both meaningful stories and isolated sentences, there is a possible alternative artifactual explanation for the finding. Since subjects in Experiments 1 and 2 were told the materials were from the writings of Shakespeare, they could have been choosing metaphors more often on the response task because they looked more like "real Shakespeare." A pilot group of subjects given only the response task with directions to check the one of the four sentences in each set $\left(M_{0}, M_{n}, N_{1}\right.$, and $\left.N_{2}\right)$ that they thought was the real quotation from Shakespeare showed that subjects chose the metaphorical sentences at greater than chance level. Since all of the actual Shakespeare quotations were metaphorical items in Experiments 1 and 2, the obtained results could be a product of this task artifact. Thus Experiment 3 was run to test this alternative explanation. It was an exact replication of Experiment 2 except that subjects were told before the response task that not all of the experimental materials actually were verbatim Shakespeare.

\section{EXPERIMENT 3}

\section{Method}

Experiment 3 was run exactly as Experiment 2 with the following exceptions: (1) There were 22 subjects, 11 hearing each of the two versions. (2) All subjects heard the four plays in the same order. (3) Included in the instructions to the response task were the following two sentences. "Caution: For experimental design reasons, some of the Shakespeare excerpts you heard were not actually original Shakespeare but rather were paraphrased by the researcher. Check the sentences below that you think you heard on the tape, not necessarily the ones you think are the original Shakespeare."

\section{Results and Discussion}

The results were tabulated and analyzed exactly as in Experiment 2; the mean numbers of correct, same-type, and opposite-type responses appear at the bottom of Table 3. There was a significantly greater number of correct recognition of metaphors than nonmetaphors $\left[F_{1}(1,21)=12.62, \quad F_{2}(1,25)=10.71, \quad \min F^{\prime}(1,46)=\right.$ $5.79, \mathrm{p}<.05]$. There were also significantly more false alarms to the opposite type of sentence for the metaphorical input sentences at the .05 level $\left[F_{1}(1,21)\right.$ $=5.76, \mathrm{~F}_{2}(1,25)=4.15$, although $\min \mathrm{F}^{\prime}(1,46)=2.41$, n.s.]. Thus, in spite of a relatively small number of subjects, the results support Experiments 1 and 2, in that metaphors were correctly recognized more frequently than nonmetaphors and the finding cannot be attributed to a response bias of choosing the response alternative perceived to be the "most Shakespearean."

\section{GENERAL DISCUSSION}

Results from all three studies consistently showed that metaphors are correctly recognized more frequently than nonmetaphors, using a forced-choice recognition memory task and Shakespearean materials. This finding sharply contradicts the 
naive theory prediction that metaphors should be more difficult, presumably because they are more exotic, symbolic, or otherwise complicated esoteric forms of language.

Just why our studies using contemporary materials (Harris, 1979; Harris et al., in press) have consistently shown no difference in memory of metaphors and nonmetaphors while the present studies of archaic literary metaphors have is not entirely clear. There are, of course, enormous differences between sentences such as "The wind tickled the wheat" and "Your bait of falsehood takes this carp of truth," although an overall difference in difficulty level or comprehensibility cannot account for the discrepancy. It may be that the hearer approaches Shakespeare or other unusually difficult language with a different response set than the normal language-reception set. There may be something about such a response set that makes metaphors more salient and thus subject to some more efficient processing strategy, although what such a process limited to literary language might be is not clear.

The findings of the present research that literary metaphors are recognized correctly more frequently than are nonmetaphors offers a psychological rationale for widespread literary use of figurative language. Not only is such language aesthetically pleasing in some ill-defined way, but it is apparently more memorable than the same thought in more prosaic terms. Thus a thought stated metaphorically may have more long-term impact on the hearer or reader.

\section{REFERENCES}

Billow, R. M. Metaphor: A review of the psychological literature. Psychological Bulletin, 1977, 84, 81-92.
Bransford, J. D., \& Johnson, M. K. Considerations of some problems of comprehension. In W. Chase (Ed.), Visual information processing. New York: Academic Press, 1973.

HARRIS, R. J. Comprehension of metaphors: A test of the twostage processing model. Bulletin of the Psychonomic Society, 1976, 8, 312-314.

HARRIS, R. J. Memory for metaphors. Journal of Psycholinguistic Research, 1979, 8, 61-71.

HaRris, R. J., Lahey, M. A., \& Marsalek, F. Metaphors and images: Rating, reporting, and remembering. In $R$. P. Honeck \& R. R. Hoffman (Eds.), The psycholinguistics of figurative language. Hillsdale, N.J: Erlbaum, in press.

Honeck, R. P., Riechmann, P., \& Hoffman, R. R. Semantic memory of metaphor: The conceptual base hypothesis. Memory \& Cognition, 1975, 3, 409-415.

Malgady, R. G., \& Johnson, M. G. Recognition memory for literal, figurative, and anomalous sentences. Bulletin of the Psychonomic Society, 1977, 9, 214-216.

Ortony, A., Reynolds, R. E., \& ARTer, J. A. Metaphor: Theoretical and empirical research. Psychological Bulletin, 1978, 85, 919-943.

VerbRUgGe, R. R. Resemblances in language and perception. In R. Shaw \& J. Bransford (Eds.), Perceiving, acting, and comprehending: Toward an ecological psychology. Hillsdale, N.J: Erlbaum, 1977.

(Received for publication January 31, 1979.) 